\title{
La literatura nos salva de los avatares de la vida cotidiana
}

\section{Literature saves us from the downs of everyday life}

\section{Isabel GARcíA AdÁNEZ}

Departamento de Filología Alemana y Filología Eslava, Universidad Complutense isagarci@ucm.es

\section{INTRODUCCIÓN}

En esta entrevista, Isabel García Adánez, ganadora del Premio Nacional a la mejor Traducción de 2020, no solo nos habla de la fascinante vida y obra de la premio nobel alemana de origen rumano Herta Müller, sino que además nos explica de forma muy gráfica, amena y sencilla alguno de los retos que plantea la traducción del alemán al español.

Palabras clave: traducción; traducción literaria.

\section{ENTREVISTA}

Fecha: 11/18/2020

Manuel de la Cruz: Bienvenida a Don de Lenguas y gracias por aceptar nuestra invitación.

Isabel García Adánez: Bueno, nada. Encantada. Gracias. 
MDLC: Lo primero, yo creo que la pregunta obligada es: Premio Nacional año 2020, ¿qué se siente?

IGA: Sí, bueno. Me hace una ilusión enorme, por supuesto. Además de que es muy especial, es un libro al que le tengo especial cariño. También es verdad que cuesta un poco creerlo. Te ves como desde fuera. Cuando el otro día vi que lo habían puesto en la página web, «La profesora Adánez...», dije: «Ay, iqué bien, una profesora de mi departamento!». Y luego pensé: «Pero ¡si soy yo!». Qué cosa más rara, ¿no? Te ves como desdoblado. Ves noticias de alguien que, bueno, eres tú pero no eres tú. Además, es un libro que salió en febrero de 2019, el premio es siempre con respecto al año anterior. Eso quiere decir que yo lo traduje, en realidad, casi en 2018. Es verdad que desde que estás trabajando en el libro hasta ahora han pasado casi dos años, uno y medio. Entonces es como algo que ha escrito y traducido otra persona. Es un poco raro.

MDLC: Bueno, te da un poco de visibilidad. La traductora que siempre está trabajando ante el ordenador. Eso te da un poquito de proyección, ¿no?

IGA: Sí, yo creo que en este caso a lo que también da mucha visibilidad es al libro, porque aunque es premio Nobel en 2009 y es una autora maravillosa, de lo mejor que hay ahora mismo en lengua alemana, no es tan conocido. En España, la literatura alemana es poco conocida en general. Como siempre, se conocen los mismos nombres. Entonces, en este caso también había mucha gente que me ha dicho: «iEnhorabuena! Además, me apetecía un montón el libro. Me lo voy a comprar. ¡Qué buena pinta! Oye, ¿y esta autora? ¡Pero si es premio Nobel!». Yo creo que me hace tanta ilusión porque lo merece, de verdad. Que si no, da pena porque se iba a perder hay un poco entre las miles de cosas que se traducen. Habría sido una pena por todo, o sea, por el propio libro y por el trabajo, que fue mucho, también lo tengo que decir.

MDLC: Además el título ya es un título muy sugerente: Siempre la misma nieve y siempre el mismo tío.

IGA: Sí, los títulos de Herta siempre son raros. Es decir, no es que sean difíciles de traducir, es muy literal y es igual de raro en español que en alemán y en cualquier otra lengua. Porque hay que haber leído el texto y, aparte, conocer un poco de su vida para ver qué significa esto. En su caso, en el artículo en el que lo explica, sí que hay un juego de palabras en rumano, por lo visto. No hay una palabra, sino dos, homófonas, para nieve y para tío, algo como «nea» para «tío» pariente, pero también «tío» en el sentido español de «tipo». Ella ahí refiere su biografía. Ella fue perseguida por el régimen rumano, procede también de una zona rural muy árida y de vida muy dura. Cuando por fin se exilió en Alemania, también lo tuvo muy difícil porque ahí la acusaron de haber sido simpatizante del régimen rumano. Ella estuvo prácticamente perseguida y amenazada de muerte hasta bien pasada la caída del muro. Entonces, ella ahí dice como que

Isabel GARCIA ADÁNEZ La literatura nos salva de los avatares de la vida cotidiana
CLINA

vol. 7-1, June 2021, 67-75

elSSN: 2444-1961

Ediciones Universidad de Salamanca - CC BY-NC-ND 
«vayas donde vayas, te encuentras siempre la misma nieve, el mismo paisaje, el mismo frío y el mismo tío». Que siempre hay un tío, un tipo, que te está vigilando, que te está haciendo la vida imposible, que te está controlando y que de alguna una manera no te está dejando vivir. Vayas donde vayas, te lo encuentras. ¿Cuántas veces te pasa en la vida que siempre te encuentras al mismo tío en diferentes sitios, porque en el fondo es lo mismo dónde estés? Ese es su tema en realidad. Este título y la extrañeza es parte de su estilo también. Lo ha dicho ella misma muchas veces, que ella escribe para no volverse loca y que ojalá no hubiera tenido que hacerlo, porque eso significaría que no habría tenido la misma nieve, el mismo tío, sino que habría tenido una vida mucho más normal y mucho más tranquila.

MDLC: La verdad es que la mirada de Herta Müller es bastante especial. Sobre todo, cuando uno lee el libro da la sensación de que lo está entendiendo todo. Pero es que después hay partes que uno, con la mirada de traductor, dice: "Qué difícil, cómo se habrá enfrentado a la traductora a este problema». Para mí, la obra mezcla tanto prosa como poesía, es un rompecabezas. ¿Cómo solucionaste todo esto sin volverte loca?

IGA: Para empezar, ya había traducido más cosas de ella y me había leído prácticamente todo. Esto, por lo menos, te da la seguridad de que cuando ves algo raro, eso ya lo has leído y sabes qué está diciendo. «Esto es nieve y esto, tío» y efectivamente. Por lo menos, lo que dice en alemán ya lo tengo claro. A mí me encanta ella, me gusta mucho su estilo, me gustan sus imágenes... Es decir, a mí ese punto surrealista que tiene no me molesta nada. Entiendo que puede haber gente a la que eso le produzca un poco de rechazo. A mí me gusta mucho también esa desnudez que tiene a veces de no añadir palabras de más. A mí, como lectora, me encantarían sus libros de todas formas. A la hora de traducir eso ayuda. Luego es cuestión de darle vueltas y más vueltas y, bueno, pues en algún momento te acaba saliendo. Casi todas las claves están siempre en el texto. Se trata de haberlo analizado, visto y reescrito muchas veces. Incluso en los casos de poesía, la poesía que incluye de otros autores, al final es cuestión de pulir, de leer, de desmenuzar, de reinventar. Yo cuando lo leo digo: «Anda, qué bien ha quedado esto» y tampoco sé muy bien cuál es el proceso. En algunos ejemplos sí me acuerdo, pero en otros pues lo veo. Los textos tienen un poquito de vida propia. Tú te pones y va saliendo, tampoco sabes muy bien cómo se ha hecho eso. Están ahí los duendecillos de la lengua que de alguna manera operan y, al final, sale.

MDLC: Claro, porque esto es un libro de no ficción, además. ¿No?

IGA: Sí. Esto es una colección de ensayos, de artículos, de algunos textos... Su discurso del Nobel un poco reelaborado. Es una mezcla, en principio, de textos breves que muchos son ensayos, pero tampoco en el sentido de texto académico, ni siquiera cuando habla de otros autores. Son un poco sus reflexiones sobre ello. "Reflexiones» igual es una buena palabra. Son sus reflexiones porque son muy autobiográficas

Isabel GARCIA ADÁNEZ La literatura nos salva de los avatares de la vida cotidiana
CLINA

vol. $7-1$, June $2021,67-75$

elSSN: 2444-1961

Ediciones Universidad de Salamanca - CC BY-NC-ND 
también. No es un ensayo en este sentido de cosas más filosóficas; al final ella escribe sobre su vida como en la ficción.

MDLC: Además, en esta obra de Herta hay como tres partes: novela, poesía y, ahora, ensayo.

IGA: Sí, ella lo trata todo. En el fondo, yo creo que toda su obra es una especie de red. Empezó escribiendo ficción, muy biográfica, pero ficción. Ella misma lo explica cómo que empezó con lo que estaba más lejos de su propia vida, que es como contarlo de forma que fuera la vida de otros. Luego se ha ido acercando, porque los ensayos explicaban su obra de creación y explican su vida y aportan muchísimos datos. En realidad lo último que ha escrito, aunque no es lo último que se ha publicado ni lo último que se ha traducido, fue la autobiografía que se llama Mi patria es una semilla de manzana, que también es un título de un verso suyo. En realidad, la autobiografía es posterior a este libro, pero se publicó antes y se tradujo antes. $\mathrm{O}$ sea, que lo último que ha escrito es lo que está en realidad más cerca de lo real, como si ella misma lo hubiera ido procesando y le hubiera como ido doliendo menos para tratarlo más de cerca. Eso leyendo se ve y se nota, pero todo eso está muy cerca temática y estilísticamente.

MDLC: La obra de Herta Müller, esta traducción en concreto, tú como traductora que, de algún modo, encarnas el espíritu de Herta, por decirlo de una manera romántica, «La autora en español del ensayo»... ¿Te ha dejado marca esta traducción? Porque hay libros que a veces marcan porque son muy profundos, el propio proceso de traducción y el meterse dentro de la obra... ¿Este libro es uno de esos libros de los que se podría decir que te han marcado?

IGA: Quizá sí. Esta es la culminación de Herta Müller porque es el quinto libro que yo hago, es el más difícil en realidad. Ayer estaba traduciendo otra cosa que no se parece absolutamente nada, y esa creatividad y libertad que ella tiene de asociación, de crear imágenes que a veces parecen que están muy alejadas, pero como a ella cabeza le va muy rápido, pues a veces hace asociaciones muy inusuales y un poco surrealistas. Entonces, ayer estaba con una cosa que no tiene nada que ver, pero de repente me salió un giro «esto quiere decir tal» y dije: «A ver si esto se va a acabar pareciendo a Herta Müller». Porque yo misma le daba un vuelo surrealista, y voy a fijarme un poco más, a ver si puedo poner una cosa menos libre y más prosaica. Eso como traductor uno debería no debería hacerlo. Siempre tiene que plegarse al texto lo más posible y uno reproduce el estilo del original, si lo haces bien. Quizá, sin querer, hay algún recurso, alguna forma de deshacer las estructuras del alemán, que hay distintas maneras. lgual de algo muy metafórico puedes buscar un giro que, aunque sea un poco más largo, gramaticalmente sea menos rarito. A mí, personalmente sí me ha marcado la lectura. Es un libro que me encanta, pero creo que en el estilo no nos debería pasar con las traducciones. Cada libro ya es su estilo, es su autor y eso te lo impone el libro.

Isabel GARCIA ADÁNEZ La literatura nos salva de los avatares de la vida cotidiana
CLINA

vol. 7-1, June 2021, 67-75

elSSN: 2444-1961

Ediciones Universidad de Salamanca - CC BY-NC-ND 
Si tú sigues el libro, tampoco te debería de pasar demasiado, pero sí que pasa a veces. Herta es mucha Herta.

Martín Azcárate: Yo me imagino que para traducir una obra de una autora con una biografía semejante, al final el traductor/a entra en diálogo muy estrecho con la autora. Imagino que, como dices, luego descubres dentro de ti una parte dedicada a esa autora que puede salir por otros sitios. Imagino que ese diálogo es lo más rico del proceso.

IGA: Sí, es lo más bonito. Efectivamente. Yo no escribo en el sentido de «obra de creación», pero a veces pienso que me gustaría escribir así. Y eso que he traducido a otros autores de los que, claro, he reproducido el estilo, pero a mí no me gustaría crear como ellos. Pero Herta Müller curiosamente sí. Para mí ya es tarde para tener una vida tan sumamente dura como para tener que encontrar esos recursos de fantasía y distanciamiento para superarla. Ella tiene, a veces, estas metáforas de la poesía de vanguardia, que en España nos pueden recordar a la Generación del 27, que conocemos, muy simbolista, ella lo hace de una manera muy natural. Ella no quiere imitar el estilo de nadie. En alguna ocasión ha dicho «a mí esto me sale así, yo no tengo voluntad de hacer un texto con metáforas medio surrealistas, pero así me sale». Ojalá pudiera yo escribir alguna vez como ella. Al final, es un gusto poder reproducir lo que se le ocurre como para que fuera una ocurrencia mía propia. Sí que es un libro muy especial. Y la pena es que sus libros ya están traducidos todos, hay que darle la lata para que escriba algo más, porque ya se me ha acabado el gusto de poder traducir textos suyos. A menos que sea retraducida, pero creo que ahora mismo no queda mucho.

MDLC: Isabel, el tema de los problemas concretos a los que te enfrentaste en esta traducción, ¿podrías citarnos alguno de esos problemas que, de alguna manera, te quitaron el sueño?

IGA: Me estás pillando. No se me ocurre ninguno inmediatamente. Una cosa que a mí me quita el sueño en general es la facilidad de formación de palabras con pocos elementos del alemán. A quienes sean traductores del inglés también les pasará. Herta Müller tiene un estilo muy desnudo, de nieve, de frío, que parece que no tiene mucha textura. Muchas veces, estas cosas del alemán están relacionadas con que, con solo cambiar el prefijo verbal, ya tiene todo un juego de palabras que en ingles sería igual si cambias los phrasal verbs o la pronunciación, y en español no lo puedes reproducir. En español pasa que, al traducir de una lengua germánica, como que te "engorda» el texto. En su caso, es muy rápido, es cambiar el prefijo, puede ser una letra o dos y ya tienes otra cosa enteramente distinta. Un proceso lingüístico muy rápido en el que no añade nada más que esos pequeños matices. Eso en español te cuesta mucho porque te alarga el texto, lo «engorda», se te va el ritmo. Ahora mismo no tengo ningún ejemplo en concreto en la cabeza, pero este es un problema en general del alemán. Yo qué sé, estaba pensando en una palabra como "sencillo», einfältig, que viene de

Isabel GARCIA ADÁNEZ La literatura nos salva de los avatares de la vida cotidiana
CLINA

vol. 7-1, June 2021, 67-75

eISSN: 2444-1961

Ediciones Universidad de Salamanca - CC BY-NC-ND 
Falte, pliegue o plica, esa definición de algo solo tiene un pliegue, y de ahí deducimos que no es complejo, pero es mucho más descriptivo en alemán, en español ya hay que valorar con «sencillo», "sencillón»... Nosotros no tenemos adjetivos tan absolutamente «asépticos», esos que tiene el alemán. Eso a veces molesta porque añades valores y cargas que el texto original no tiene. Es lo que más difícil me parece de adaptar del alemán, casi siempre. Herta Müller como, además, juega mucho con eso, te da más lata todavía. Pero creo que es una cuestión, sobre todo, de estructuras de la lengua. Por ejemplo, a mí lo de imaginar o rimar, de alguna manera, me resulta más fácil porque yo no vengo de la filosofía, sino de la filología, del análisis de la lengua, donde quizá uno igual está más familiarizado con cierto tipo de estructuras. Me gusta más la parte lúdica del lenguaje. También está la cuestión de si debemos crear composiciones nuevas en español sobre las estructuras alemanas, aunque luego no suenen a español. A mí personalmente no me gusta producir, palabras raras que no son naturales y estropean un poco el texto, porque hacen pensar al lector que «el alemán es muy raro», y no lo es en absoluto, es natural.

MDLC: Aquí, aparte de un gran trabajo de documentación, también he visto que te has enfrentado a la poesía experimental, a los autores que ama Herta Müller. Eres traductora de los autores que le gustan a Herta Müller también. Porque he visto cosas que me resultaron raras, incluso, de leer en español.

IGA: Es que la poesía experimental... Es súper curioso, porque los textos de otros autores... Ella habla de sus grandes referentes que, por lo general, también son autores que han sufrido algún tipo de acoso, persecución, que tienen una posición muy política ante la escritura, pero que también juegan con el lenguaje. Eso es lo que les salvó a todos de la vida que tuvieron. Ella en sus propios ensayos explica los mecanismos lingüísticos que admira en los otros. Ahí la propia autora ya te da claves de qué es lo que te vas a encontrar. En el caso de la poesía experimental de Oskar Pastior tiene dos capítulos enteros que contienen, por lo menos, una decena de poemas experimentales muy complicados y curiosos. Hay una parte en la que ella dice «en realidad, en Rumania como estamos obligados a improvisar constantemente, a usar cualquier cosa para convertirla en otra cosa y que funcione, lo que hacíamos era una especie de collage de cosas en la poesía», que es lo que hace Pastior también. Cosas que en principio no van juntas, pero tú las pones juntas y producen un buen resultado. En el lenguaje imitan eso. Es como si cortara la frase, la palabra en pedacitos y la vuelve a componer de una forma diferente. En español vamos a hacer lo mismo. Al final, de alguna forma te sale, incluso la poesía experimental, que a mí me gusta leerla y analizarla. Yo hacía esa clase de comentario de texto. Si tú analizas bien el texto y entiendes cómo está construido y cuáles son los recursos, luego se trata de intentar reproducirlos. Creo que ahí me ha ayudado mucho el ser filóloga. Yo estudié toda primaria, secundaria y el bachillerato alemán, donde se da muchísima importancia al comentario de texto. He hecho análisis de texto hasta el aburrimiento y era lo que más me gustaba. Creo

Isabel GARCIA ADÁNEZ La literatura nos salva de los avatares de la vida cotidiana
CLINA

vol. 7-1, June 2021, 67-75

elSSN: 2444-1961

Ediciones Universidad de Salamanca - CC BY-NC-ND 
que por eso estudié lo que estudié y me he dedicado a esto. Si estás acostumbrado a leer eso, lo sabes ver y lo sabes, o intentas, reproducir. Quizá pasa como cuando oyes obras de música contemporánea y no te gustan o no te dicen nada, porque no sabes lo en qué tienes que fijarte o cómo abordarlas. Cuando lo sabes y entiendes un poco el mecanismo de lo que tienes que estar escuchando, te es mas fácil reproducirlo porque, al menos, sabes de dónde salen las cosas. En ese sentido, la autora ayuda mucho. Sus propios textos ayudan a ver cómo los tienes que abordar. Ella es filóloga también, aunque no ejerce como tal. En realidad ella hizo Filología y creo que también se dedica a lo que se dedica porque la Filología le sirvió.

MDLC: Entonces, la verdad es que tienes una relación desde este punto de vista con la autora. ¿Tienes otro tipo de relación con ella? ¿Has podido hablar con ella?

IGA: Sí, bueno. Mi relación con ella es muy indirecta. A mí no se me ocurriría llamar o escribirla. Además, no se puede, es a través de su agente de la editorial. No se me ocurriría abordarla con una duda, sería molestar. Sí que la conozco. Cuando ha venido a España, a Madrid o Barcelona, a algún acto he estado y me la han presentado, he hablado con ella dos palabras. El otro día a través de la editorial la avisaron, le dijeron lo del premio y ella contestó enseguida, se puso muy contenta y dijo que se acordaba de mí y me mandó muchos abrazos: «Espero podérselos dar alguna vez en persona». El premio le ha hecho ilusión. Espero poderla encontrar otra vez y verla en persona, pero a mí me impone muchísimo y eso que es muy menudita, una persona muy frágil. Pero es todo un carácter, muy valiente y con mucho sentido del humor. Yo me arrodillo a sus pies. Sí que la admiro mucho por todo.

MDLC: Ahora estás también metida en otros proyectos. Tú último proyecto es moderar alguna mesa en el Festival EÑE en Madrid, que está teniendo lugar esta semana. Tienes una relación muy estrecha con la literatura. ¿Podríamos decir que tu vida es literatura?

IGA: Bueno, no sé. De una manera mega prosaica en comparación con Herta Müller, la literatura nos salva de los avatares de la vida cotidiana. Siempre me ha gustado mucho leer. Como he tenido una formación muy enfocada a los textos y a leer, y siempre he tenido buenos profesores de literatura, me interesa más, me gusta más, me llama más... Ojalá me pudiera dedicar solo a eso. También es verdad que no hay tanta gente que se dedique a la literatura alemana en España, entonces en cuanto hay cosas de literatura alemana, de traducción del alemán, nos encontramos mucho los mismos porque somos relativamente pocos.

MDLC: Te tengo que hacer una pregunta. Como eres una mujer todoterreno, porque estás metida en muchos proyectos... ¿ahora en qué proyectos estás metida de traducción? ¿Qué tienes entre manos?

Isabel GARCIA ADÁNEZ La literatura nos salva de los avatares de la vida cotidiana
CLINA

vol. 7-1, June 2021, 67-75

eISSN: 2444-1961

Ediciones Universidad de Salamanca - CC BY-NC-ND 
IGA: Tengo varios a la vez. Tengo una parte que falta por traducir de los Cuadros de viaje de Heine que traduje hace años, pero no enteros, no toda la colección completa. Sí que se va a publicar ahora completa en la editorial La línea del horizonte. Tengo encargados para Alianza unos relatos de Stefan Zweig y Arthur Schnitzler, dos libros de cosas no muy largas, pero dos clásicos. Luego tengo un gran encargo, en el sentido de volumen también, de un libro que se llama Das kalte Blut (La sangre fría), libro que aquí no es tan conocido, pero en Alemania sí, porque el autor es director de cine, es muy conocido como guionista. Es una novela recoge casi toda la historia alemana del siglo XX. Es un volumen de más de mil páginas que me mira desde la estantería con cara de amenaza, pero también me apetece mucho porque es un estilo muy ágil, tiene muchas partes de cultura alemana contemporánea. A veces pienso: «Qué bien para clase», porque este campo es muy poco conocido. También me apetece mucho porque me gusta esta literatura con dimensión social y política como lectora. Sí, me apetece mucho. Se me ocurren muchas más cosas, pero creo que la vida no me va a dar.

MDLC: Muchísimas gracias, Isabel. Se nos ha acabado el tiempo. Gracias por haber aceptado esta entrevista. Esta es tu casa, estás invitada para venir. Es un placer poder hablar con una traductora tan experimentada como tú, de la que estamos aprendiendo todos constantemente y van a aprender nuevas generaciones como Martín.

MA: Te lo agradezco, se me ha acabado la tinta del bolígrafo de tomar apuntes. Muy interesante.

IGA: Gracias a ti.

\author{
Entrevista: «Manuel de la Cruz, Martín Azcárate» \\ Transcripción: Beatriz Guerrero García \\ Enlace: https://www.ivoox.com/entrevista-a-isabel-garcia-adanez-audios-mp3_rf_60628257_1.html \\ Duración: 28:07:00
}

\title{
NOTA BIOGRÁFICA
}

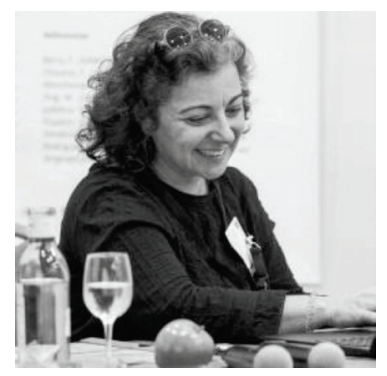

Isabel García Adánez (Madrid, 1972) es licenciada en Filología Alemana y Española y doctora en Filología Alemana, así como diplomada en Piano y en Teoría de la música. Es profesora y directora del Departamento de Filología Alemana y Filología Eslava de la Universidad Complutense de Madrid y ha traducido a numerosos autores de lengua alemana, principalmente de los siglos $x \mid x$ y $x x$. 
Isabel García Adánez:

https://www.ucm.es/filologiaalemanayfilologiaeslava/isabel-garcia-adanez

\section{BIBLIOGRAFÍA}

García Adánez, Isabel: «'Beides geht nicht'. Der Fall Herta Müller», en: Blanco Hölscher, M. y Jurcic, C. (Eds.), Narrationen in Bewegung. Deutschsprachige Literatur und Migration, Bielefeld, Aisthesis, 2019, pp. 97-110. ISBN 978-38498-1309-3.

García Adánez, Isabel: «Nueve sílabas volando entre las flores, o: Cómo enseñar criterios de traducción a raíz de un ejemplo de Las penas del joven Werther», en: Fortea, C. (coord.) El viaje de la literatura, Madrid, Cátedra, 2018, págs. 101-120. ISBN 978-84-376-3868-3.

García Adánez, Isabel y Sporrer, Sieglinde: «¿Muchos cocineros estropean el guiso? La traducción colectiva en clase», en: Reflexiones en torno a la Traducción e Interpretación del/al alemán Überlegungen zur Translationswissenschaft im Sprachenpaar Spanisch-Deutsch, Frankfurt et al., Peter Lang, 2015. ISBN 978-3-631-65975-5.

García Adánez, Isabel: «Heinrich Böll y la primera posguerra«, en: Turia 115 (2015), págs. 196205. ISSN: 0213-4373.

García Adánez, Isabel: «Esas inmensas minorías... El alemán de Herta Müller», en: Vasos Comunicantes 45 (2015), págs. 43-56.

García Adánez, Isabel: «Las moradas del traductor. Lengua, identidad y utopía en la traducción», en: Vasos Comunicantes 44 (2014), pp. 93-104.

García Adánez, Isabel: «Estrategias de traducción ante las alteraciones de la lengua estándar y los juegos de palabras", en: HYPERLINK "https://dialnet.unirioja.es/servlet/revista?codigo=5880" Education in the knowledge society (EKS), HYPERLINK "https://dialnet.unirioja. es/ejemplar/298637" Vol. 13, № 1, 2012 (número monográfico dedicado a Traducción literaria: Expandiendo los límites), pp. 209-235, ISSN-E: 1138-9737.

García Adánez, Isabel: «El lenguaje no verbal en siete traducciones de La montaña mágica», in: Jirku, B. und van Lawick, H. (Hrsg.): Übersetzen als Performanz, Berlín/Münster, 2012, 171 189. ISBN: 978-3-643-50451-7.

García Adánez, Isabel: «Cuando faltan las palabras. El traductor ante las diferencias culturales», en: Martos Ramos, J., Trapassi, L., García Adánez, I. y Borrero Zapata, V. (eds.): Diálogos interculturales. Lenguas, literaturas y sociedad. Barcelona, Anthropos, 2011, págs. 141160. ISBN: 978-84-7658-956-4.

García Adánez, Isabel: «Los ojos de Olimpia. Diez versiones de una escena de terror», en: 1611. Revista de Historia de la Traducción 5 (2011), Universidad de Barcelona, págs.1-11. ISSN: 1988-2963. http://www.traduccionliteraria.org/1611/art/garciaadanez.htm

Isabel GARCIA ADÁNEZ La literatura nos salva de los avatares de la vida cotidiana
CLINA

vol. 7-1, June 2021, 67-75

elSSN: 2444-1961

Ediciones Universidad de Salamanca - CC BY-NC-ND 